\title{
Consumption of Sugar-Sweetened Beverages Among US Adults in 6 States: Behavioral Risk Factor Surveillance System, 2011
}

Sohyun Park, PhD; Liping Pan, MD, MPH; Bettylou Sherry, PhD, RD; Heidi M. Blanck, PhD

Suggested citation for this article: Park S, Pan L, Sherry B, Blanck HM. Consumption of Sugar-Sweetened Beverages Among US Adults in 6 States: Behavioral Risk Factor Surveillance System, 2011. Prev Chronic Dis 2014;11:130304. DOI: http://dx.doi.org/10.5888/pcd11.130304 it:

PEER REVIEWED

\section{Abstract}

\section{Introduction}

Sugar-sweetened beverage (SSB) intake is linked to weight gain. Our objective was to examine state-specific SSB intake and behavioral characteristics associated with SSB intake.

\section{Methods}

We used data from the 2011 Behavioral Risk Factor Surveillance System for 38,978 adults aged 18 years or older from 6 states: Delaware, Hawaii, Iowa, Minnesota, New Jersey, and Wisconsin. Multivariate logistic regression was used to estimate adjusted odds ratios for characteristics associated with SSB intake from regular soda and fruit drinks.

\section{Results}

Overall, 23.9\% of adults drank SSBs at least once a day. Odds of drinking SSBs 1 or more times per day were significantly greater among younger adults; males; non-Hispanic blacks; adults with lower education; low-income adults or adults with missing income data; adults living in Delaware, Iowa, and Wisconsin versus those living in Minnesota; adults with fruit intake of less than 1 time a day versus 1 or more times a day; adults who were physically inactive versus highly active adults; and current smokers versus nonsmokers. Odds for drinking SSBs 1 or more times per day were significantly lower among adults with $100 \%$ fruit juice intake of less than 1 time per day versus 1 or more times per day and among adults who drank alcohol versus those who did not drink alcohol.

\section{Conclusions}

SSB intake varied by states and certain sociodemographic and behavioral characteristics. States can use findings from this study to tailor efforts to decrease SSB intake and to encourage consumption of more healthful beverages (eg, water) among their high-risk populations.

\section{Introduction}

Sugar-sweetened beverages (SSBs) contribute significant number of calories to diets of US adults (1). The 2010 Dietary Guidelines for Americans define SSBs as "liquids that are sweetened with various forms of sugars that add calories. These beverages include, but are not limited to, soda, fruit-ades and fruit drinks, and sports and energy drinks" (2). In the National Health and Nutrition Examination Survey (NHANES) 2005-2008, about half of Americans drank SSBs on any given day (3). SSB intake in adults is associated with obesity (4-6); type 2 diabetes (6-8); increased risk for cardiovascular disease (6,9-11), nonalcoholic fatty liver disease (12), kidney disease (13), and gout (14); and decreased diet quality (15).

Several studies have examined sociodemographic characteristics associated with SSB intake among a nationally representative sample of US adults (3,16-19). State-specific information on SSB intake is limited, and only a few studies have examined associations between behavioral factors and SSB intake among US adults. For example, a study reported that obese adults and those who were not trying to lose weight had higher mean calorie intake from SSBs (17). Another study found no differences in SSB intake by physical activity and smoking among adults aged 20 to 39 years 
(19). Identifying behavioral factors and state-specific information associated with SSB intake can enable states to target intervention efforts to decrease SSB intake among high-risk populations. Additionally, the Centers for Disease Control and Prevention (CDC) has selected reducing SSB intake as a target behavior for preventing and controlling obesity and supports states in working on state-level data to prioritize subgroups that may need more targeted interventions for SSB reduction. State-based surveillance data are needed to document baseline and postintervention SSB consumption to monitor the impact of CDC funding of state-based interventions to prevent and control obesity.

This study provides a summary of the first available standardized data for the 6 states that used the standardized Behavioral Risk Factor Surveillance System (BRFSS) Optional Module for assessing SSB intake: Delaware, Hawaii, Iowa, Minnesota, New Jersey, and Wisconsin. Our objective was to describe SSB intake (regular soda/fruit drinks) in adults by using a state-specific data source and to examine the associations between SSB intake and sociodemographic and behavioral characteristics.

\section{Methods}

\section{Sample and survey administration}

This cross-sectional study was based on 2011 BRFSS data. BRFSS is a state-based, telephone interview survey conducted annually by CDC and state health departments and is designed to assess a range of respondents' health conditions and behaviors related to public health issues. It uses a multistage cluster sampling design with randomdigit dialing (including landline and cellular telephones) to select a sample that represents the civilian, noninstitutionalized adult population in each of the 50 states, the District of Columbia, and 3 US territories. Poststratification weights are used to adjust for nonresponse, noncoverage, and uneven selection of the population to generate demographic distributions that closely match the state population. Detailed information on validity of measures and survey data is available elsewhere $(20,21)$. Every year, several Optional Modules are available on BRFSS, and states decide whether to include these as part of their survey. A standardized Optional Module for assessing soda and fruit drink intake as surrogates for total SSB intake was made available on the 2011 BRFSS, and the 6 states included in this study used this module. Although this SSB Optional Module was offered to states in 2012, we used 2011 data to provide information for the initial year of module use and to include key behavioral variables (eg, fruit and vegetable intake, physical activity) that were not collected in 2012. A total of 43,157 adults aged 18 years or older completed the SSB Optional Module. For this analysis, 4,179 adults with missing data on regular soda (soda sweetened with various forms of sugars) or fruit drink intake were excluded, resulting in a final analytic sample of 38,978 adults. In comparing the analytic sample with adults who were excluded from the study because of missing outcome data, the analytic sample had a slightly lower proportion of adults aged 70 years or older and a higher proportion of nonHispanic whites; the sample had no difference in sex. Additionally, unknown values and missing data for exposure variables ranged from $0.2 \%$ to $5.5 \%$ (the latter for race/ethnicity) and were excluded from analyses when the variable was used.

\section{Outcome variable}

The outcome measure was SSB intake. Respondents were asked "About how often do you drink regular soda or pop that contains sugar? Do not include diet soda or diet pop," and "About how often do you drink sweetened fruit drinks, such as Kool-Aid, cranberry juice, and lemonade? Include fruit drinks you made at home and added sugar to." For each question, respondents reported number of times per day, per week, or per month they consumed these beverages. Weekly or monthly intake was converted to daily intake (dividing weekly intake by 7 and monthly intake by 30). To calculate total SSB intake frequency, the frequency of consumption of regular soda and fruit drinks was summed. Of note, although past month SSB intake was converted to daily consumption, this may not capture day-to-day variability in consumption. For $\chi^{2}$ tests, 4 mutually exclusive SSB intake categories were created for per-day consumption (o, >0 to $<1,1$ to $<2$, and $\geq 2$ times). The cutpoint of 1 time per day was chosen to define daily intake, and the cutpoint of 2 times per day was based on the estimated 85th percentile of energy intake from SSB on a given day (about two 12-oz cans of soda) among Americans $(3,22)$.

\section{State and sociodemographic and behavioral variables}

Mutually exclusive response categories were created for exposure variables. Sociodemographic variables included were

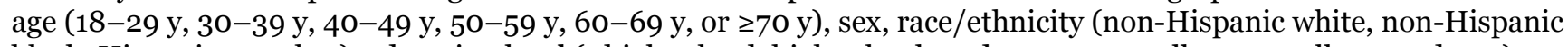
black, Hispanic, or other), education level ( $<$ high school, high school graduate, some college, or college graduate), marital status (married, single, divorced/separated/widowed), and annual household income $(<\$ 25,000, \$ 25,000$ $-\$ 49,999, \$ 50,000-\$ 74,999, \geq \$ 75,000$, or don't know/refused/missing). Because a relatively large proportion $(\sim 14 \%)$ of adults had “don't know/refused/missing” responses for annual household income, we did not exclude these individuals from our analyses. Instead, we created an additional category for these adults and included them as such in our analyses.

We selected behavioral variables for study on the basis of a literature review $(15,17,19)$. Furthermore, the cutoffs for the consumption of fruits ( $<1$ time/d or $\geq 1$ time/d), $100 \%$ fruit juice $(<1$ time/d or $\geq 1$ time/d), and vegetables $(<3$ times/d 
or $\geq 3$ times/d) were based on a previous study (23). Leisure-time physical activity was categorized as highly active ( $>300 \mathrm{~min} / \mathrm{wk}$ ), active (150-300 $\mathrm{min} /$ wk physical activity), insufficiently active (11-149 $\mathrm{min} / \mathrm{wk}$ physical activity), and inactive (no physical activity). Smoking status was categorized as nonsmoker, former smoker, or current smoker. Alcohol drinking was categorized as no drinking, any drinking ( $\geq 1$ drink of any alcoholic beverage during the past month but not heavy drinking), and heavy drinking ( $>2$ drinks/d for men and $>1$ drink/d for women). Body mass index (BMI) was calculated from self-reported weight and height $\left(\mathrm{kg} / \mathrm{m}^{2}\right)$, and weight status was categorized as underweight (BMI <18.5), normal weight (BMI 18.5-24.9), overweight (BMI 25.0-29.9), or obese (BMI $\geq 30$ ) (24).

\section{Statistical analysis}

We used $\chi^{2}$ tests to examine the unadjusted bivariate relationship between frequency of SSB intake and the sociodemographic and behavioral variables described above. The cutoff for statistical significance was $P<.05$. Multivariable logistic regression was used to estimate adjusted odds ratios and 95\% confidence intervals for associations between the likelihood of drinking SSB 1 or more times per day and state and sociodemographic and behavioral characteristics. Data were pooled into 1 model with state as a variable in that model $(n=32,374$ adults $)$. The age, sex, and race/ethnicity distributions of the respondents included in the model were similar to those in the overall analytic sample $(\mathrm{n}=38,978)$. The sample weight variable was applied to all analyses to provide valid estimates for the civilian noninstitutionalized adult population in each state. All statistical analyses were performed using SAS-Callable SUDAAN version 9.3 (SAS Institute, Cary, North Carolina) and incorporated appropriate procedures to account for the complex sample design.

\section{Results}

Only 30\% of adults reported never drinking SSBs (per day, week, or month). Overall, 70\% reported drinking any SSB per day; $23.9 \%$ reported drinking SSBs at least once a day, and $10.7 \%$ reported doing so at least twice a day. By state, the prevalence of SSB intake 2 or more times per day was $14.4 \%$ for Iowa, $13.0 \%$ for Wisconsin, $10.9 \%$ for Delaware, 10.4\% for Hawaii, 9.7\% for Minnesota, and 8.5\% for New Jersey (Table 1). SSB consumption varied by all sociodemographic and behavioral characteristics studied ( $\chi^{2}$ tests, $P<.05$ for all variables). The proportion of adults drinking SSBs 2 or more times per day was highest among adults in Iowa, young adults, men, non-Hispanic blacks, adults with a less than high school education, single adults, and adults in the lowest-income category (Table 1). Regarding behavioral characteristics, the proportion of adults drinking SSBs 2 or more times per day was highest among adults consuming fruits less than once a day, 100\% fruit juice less than once a day, and vegetables less than 3 times per day and among physically inactive adults, current smokers, adults who did not drink alcohol, and obese adults (Table 2).

Multivariable logistic regression results showed that odds for drinking SSBs 1 or more times per day were significantly higher among adults in Delaware, Iowa, and Wisconsin versus adults in Minnesota; among younger adults than among those aged 70 or older; among men than among women; among non-Hispanic blacks than among non-Hispanic whites; among adults with lower education levels versus those who were college graduates; among adults with lower household income or with "missing/don't know/refused" income data than among those with an income of \$75,000 or more; among adults who consumed fruit less than once a day than among those who consumed fruit 1 or more times per day; among adults who were physically inactive than among those who were highly active; and among current smokers than among nonsmokers. In contrast, odds for drinking SSBs 1 or more time per day were significantly lower among adults consuming $100 \%$ fruit juice less than once per day than among those consuming $100 \%$ fruit juice 1 or more times per day and among those with any or heavy alcohol drinking than among nondrinkers (Table 3).

\section{Discussion}

Although only 2 types of SSBs (regular soda and fruit drinks) were included in our analyses, the prevalence of adults consuming any SSB per day was somewhat higher in our study (70\%) compared with that reported in the NHANES 2005-2008 data, which showed that about 50\% of adults aged 20 years or older consumed SSBs daily (3). In our study, $23.9 \%$ of adults consumed SSBs 1 or more times per day, with $10.7 \%$ doing so 2 or more times per day. This finding is similar to SSB intake reported for New York State adults, in which 20.5\% consumed SSBs (regular soda, fruit drinks, sports drinks, or sweet tea) 1 or more times per day in the 2009 New York State BRFSS, which used 2 questions (25). In contrast, reported SSB intake was higher among Indiana adults in the 2011 Indiana BRFSS, which used 1 question; 64.9\% Indiana adults drank SSBs (eg, soda, fruit drinks, sweet tea, sports drinks, energy drinks, coffee drinks) once or more per day, and 35.1\% drank SSB twice or more per day (26). Discrepancies between studies could be due to variability in types of SSBs included in the questions used in BRFSS telephone surveys or variability in study samples because we pooled data from 6 states. The NHANES study used 24-hour diet recall for several types of SSB options, whereas the BRFSS is based on an abbreviated food-frequency question capturing only 2 types of SSBs to determine frequency of SSB consumption in the past month. Furthermore, we found that adults who lived in Delaware, Iowa, or Wisconsin had higher odds for drinking SSBs once or more a day than those who lived in Minnesota; however, the underlying reasons for these differences are unclear. Despite the variability of subgroup SSB consumption, the 
prevalence of SSB intake among US adults suggests a need for some adults to reduce their calorie intake from added sugars per the Dietary Guidelines for Americans 2010 (2). Thus, public health efforts to decrease SSB intake among high consumers of SSBs may be one strategy to reduce calorie consumption.

Similar to our findings, findings of previous studies showed that SSB intake was higher among younger adults, men, non-Hispanic blacks, adults with a less than high school education, and lower-income adults $(3,17)$. We found that age was an important factor with the odds of consuming SSBs 1 or more times per day being more than 3 times higher among those aged 18 to 29 years than among those aged 70 years or older. One potential explanation for high SSB consumption may be lack of knowledge, because the sociodemographic characteristics of high SSB consumers in our study are somewhat similar to the characteristics of subpopulations who are not aware of calorie content of SSBs described in other studies. For example, 1 study reported that only $20 \%$ of adults knew the approximate calorie content of a 24-ounce soda, and the proportion of adults who knew the approximate calorie content of a 24-ounce soda was lowest among non-Hispanic blacks, those with a less than high school education, and those with lower household income (27). Another study conducted in the rural lower Mississippi Delta that did not specifically address SSB knowledge found that adults in the lowest health literacy category consumed 230 kilocalories (kcal) per day of SSBs, whereas those in the adequate health literacy category consumed 111 kcal per day of SSBs (28). To reduce disparities in SSB intake, targeted intervention efforts to reduce SSB intake among these high consumers may be needed.

To our knowledge, there is limited information on behavioral factors associated with SSB intake. We found that lower consumption of fruits and higher consumption of $100 \%$ fruit juice were significantly associated with greater odds for SSB intake at least once per day, but vegetable intake was not associated with daily SSB intake. Sharkey and colleagues reported that among rural adults, SSB intake was higher among those who consumed fewer than 5 servings per day of fruits and vegetables compared with those who consumed 5 or more servings per day (15). However, SSB intake was not significantly associated with fruit and vegetable intake among urban adults living in Texas (15). In this study, the odds for consuming SSBs 1 time or more per day were higher among physically inactive adults and current smokers. In contrast to our findings, Bermudez et al reported that SSB intake was not associated with physical activity and smoking status among US adults aged 20 to 39 years (19). Discrepancies between studies could be due to a difference in age of study populations or types of SSB included in the definition. For example, Bermudez et al included regular carbonated drinks or sodas, fruit drinks, and artificially flavored drinks, whereas we included regular soda and fruit drinks. In our study, alcohol drinkers had lower odds for consuming SSB daily compared with nondrinkers. It is possible that nondrinkers may choose to consume SSB instead of alcoholic beverages. Bleich and colleagues also found low consumption of alcohol among SSB consumers and reported that only $23 \%$ US adults who consumed at least one SSB per day drank alcohol (17).

Our study has several limitations. First, BRFSS information is self-reported, which could result in response bias in recall or social desirability. However, other studies have shown that estimates of beverage intake derived from responses to food-frequency questionnaires were similar to estimates derived from responses to 24-hour diet recalls or to food records (29,30). For example, a correlation coefficient between the food-frequency questionnaire and 24-hour diet recall for mean intake of SSB was 0.69 in a previous study (30). Second, only 2 types of SSBs (regular soda and fruit drinks) were available in the data set. However, these 2 SSBs represented the most commonly consumed types of SSBs among adults $(16,17)$. Third, we are aware of 7 states (Alaska, California, Colorado, Connecticut, Indiana, New York, and Rhode Island) that used different SSB questions as State Added Questions in 2011. Because the questions were not the same, we were not able to include data from these additional states. We used a convenience sample, so our sample does not represent the entire US adult population, which limits the generalizability of our findings. Fourth, SSB consumption was surveyed in terms of frequency, so we cannot quantify associations between the volume of SSB consumption and the covariates of study. Fifth, about 10\% of adults were excluded from the study because of missing SSB intake data, and the analytic sample had a slightly lower proportion of adults aged 70 years or older and a higher proportion of non-Hispanic whites. However, this exclusion would have minimal influence on the results, because SSB intake is higher among younger adults and lower among non-Hispanic whites based on findings of a previous study (3). Last, the associations are cross-sectional and do not permit assessment of causality or ascertaining the direction of the association.

In conclusion, about 1 in 4 adults consumed regular soda or fruit drinks at least once a day, and almost 1 in 9 did so at least twice daily. Additionally, our study showed that daily SSB intake varied by state and was notably higher among younger adults, men, non-Hispanic blacks, adults with lower education levels, and adults with lower household income or with missing income data. We also found increased odds of consuming SSBs 1 or more times per day among adults with fruit intake less than once a day, those who did not participate in leisure-time physical activity weekly, and current smokers; odds were lower among adults who consumed 100\% fruit juice less than once a day and among alcohol drinkers. Various geographic, sociodemographic, and behavioral factors were associated with SSB intake in our study. States included in our analyses, in particular those with a higher prevalence of daily SSB intake, can use this data to guide their decisions about developing targeted interventions for improved nutrition as part of an obesity strategy, for example to decrease SSB intake and encourage the consumption of more healthful beverages (eg, plain water) among high-risk populations (eg, men, smokers). Other states could use these findings to educate potential high 
consumers of SSBs in their state about reducing SSB intake. Furthermore, states may consider using standardized SSB questions such as the BRFSS Optional Module to help monitor change over time. Where program evaluation is lacking, surveillance data can be helpful to evaluate community and state programs (eg, the Community Transformation Grant, Communities Putting Prevention to Work) and will allow comparisons of SSB intake across states.

\section{Acknowledgments}

We thank the participants in 6 states and BRFSS coordinators, project coordinators, and nutrition coordinators in 6 states: Fred Breukelman in Delaware; Florentina Reyes-Salvail in Hawaii; Donald H. Shepherd in Iowa; Nagi Salem and David Simmons in Minnesota; Kenneth J. O’Dowd, Erin Bunger, and Neetu Jain in New Jersey; and Anne Ziege and Mary Pesik in Wisconsin. This research received no specific grant from any funding agency in the public, commercial, or nonprofit sectors. Dr Sherry has since retired from CDC.

\section{Author Information}

Corresponding Author: Sohyun Park, PhD, Division of Nutrition, Physical Activity, and Obesity, National Center for Chronic Disease Prevention and Health Promotion, Centers for Disease Control and Prevention, 4770 Buford Highway, NE, Atlanta, GA 30341, Mailstop F77. Telephone: 770-488-5163. E-mail: spark3@cdc.gov.

Author Affiliations: Liping Pan, Bettylou Sherry, Heidi M. Blanck, Centers for Disease Control and Prevention, Atlanta, Georgia.

\section{References}

1. Welsh JA, Sharma AJ, Grellinger L, Vos MB. Consumption of added sugars is decreasing in the United States. Am J Clin Nutr 2011;94(3):726-34. CrossRef if PubMed it

2. US Department of Agriculture, US Department of Health and Human Services. Dietary guidelines for Americans, 2010. 7th edition, Washington (DC): US Government Printing Office; 2010.

http://health.gov/dietaryguidelines/dga2010/dietaryguidelines2010.pdf. Accessed March 4, 2014.

3. Ogden CL, Kit BK, Carroll MD, Park S. Consumption of sugar drinks in the United States, 2005-2008. NCHS Data brief no. 71; 2011. http://www.cdc.gov/nchs/data/databriefs/db71.pdf. Accessed March 3, 2014.

4. Ebbeling CB, Feldman HA, Osganian SK, Chomitz VR, Ellenbogen SJ, Ludwig DS. Effects of decreasing sugarsweetened beverage consumption on body weight in adolescents: a randomized, controlled pilot study. Pediatrics 2006;117(3):673-80. CrossRef if PubMed it

5. Malik VS, Schulze MB, Hu FB. Intake of sugar-sweetened beverages and weight gain: a systematic review. Am J Clin Nutr 2006;84(2):274-88. PubMed ith

6. Malik VS, Hu FB. Sweeteners and risk of obesity and type 2 diabetes: the role of sugar-sweetened beverages. Curr Diab Rep 2012;12:195-203. CrossRef í PubMed if

7. Malik VS, Popkin BM, Bray GA, Despres JP, Willett WC, Hu FB. Sugar-sweetened beverages and risk of metabolic syndrome and type 2 diabetes: a meta-analysis. Diabetes Care 2010;33(11):2477-83. CrossRef

8. de Koning L, Malik VS, Rimm EB, Willett WC, Hu FB. Sugar-sweetened and artificially sweetened beverage consumption and risk of type 2 diabetes in men. Am J Clin Nutr 2011;93(6):1321-7. CrossRef it PubMed ith

9. Duffey KJ, Gordon-Larsen P, Steffen LM, Jacobs DR Jr, Popkin BM. Drinking caloric beverages increases the risk of adverse cardiometabolic outcomes in the Coronary Artery Risk Development in Young Adults (CARDIA) Study. Am J Clin Nutr 2010;92(4):954-9. CrossRef it PubMed it

10. Stanhope KL, Bremer AA, Medici V, Nakajima K, Ito Y, Nakano T, et al. Consumption of fructose and high fructose corn syrup increase postprandial triglycerides, LDL-cholesterol, and apolipoprotein B in young men and women. J Clin Endocrinol Metab 2011;96(10):E1596-605. CrossRef 倍 PubMed i

11. de Koning L, Malik VS, Kellogg MD, Rimm EB, Willett WC, Hu FB. Sweetened beverage consumption, incident coronary heart disease, and biomarkers of risk in men. Circulation 2012;125(14):1735-41, S1.

12. Ouyang X, Cirillo P, Sautin Y, McCall S, Bruchette JL, Diehl AM, et al. Fructose consumption as a risk factor for non-alcoholic fatty liver disease. J Hepatol 2008;48(6):993-9. . CrossRef it PubMed it

13. Bomback AS, Derebail VK, Shoham DA, Anderson CA, Steffen LM, Rosamond WD, et al. Sugar-sweetened soda consumption, hyperuricemia, and kidney disease. Kidney Int 2010;77(7):609-16. . CrossRef 偣 PubMed 原

14. Choi HK, Curhan G. Soft drinks, fructose consumption, and the risk of gout in men: prospective cohort study. BMJ 2008;336(7639):309-12. . CrossRef is PubMed id 
15. Sharkey JR, Johnson CM, Dean WR. Less-healthy eating behaviors have a greater association with a high level of sugar-sweetened beverage consumption among rural adults than among urban adults. Food Nutr Res 2011;55.

16. Kit BK, Fakhouri TH, Park S, Nielsen SJ, Ogden CL. Trends in sugar-sweetened beverage consumption among youth and adults in the United States: 1999-2010. Am J Clin Nutr 2013;98(1):180-8. CrossRef it PubMed it

17. Bleich SN, Wang YC, Wang Y, Gortmaker SL. Increasing consumption of sugar-sweetened beverages among US adults: 1988-1994 to 1999-2004. Am J Clin Nutr 2009;89(1):372-81. CrossRef it PubMed ith

18. Storey ML, Forshee RA, Anderson PA. Beverage consumption in the US population. J Am Diet Assoc 2006;106 (12):1992-2000. . CrossRef i PubMed it

19. Bermudez OI, Gao X. Greater consumption of sweetened beverages and added sugars is associated with obesity among US young adults. Ann Nutr Metab 2010;57(3-4):211-8. CrossRef if PubMed it

20. Nelson DE, Holtzman D, Bolen J, Stanwyck CA, Mack KA. Reliability and validity of measures from the Behavioral Risk Factor Surveillance System (BRFSS). Soz Praventivmed 2001;46( Suppl 1):S3-42. PubMed it

21. Behavioral Risk Factor Surveillance System. Atlanta (GA): US Department of Health and Human Services, Centers for Disease Control and Prevention. http://www.cdc.gov/brfss/index.htm. Accessed March 4, 2014.

22. USDA National Nutrient Database for Standard Reference. Release 26. Nutrient Data Laboratory, US Department of Agriculture, Agricultural Research Service. http://ndb.nal.usda.gov/. Accessed March 4, 2014.

23. Grimm KA, Blanck HM. Survey language preference as a predictor of meeting fruit and vegetable objectives among Hispanic adults in the United States, Behavioral Risk Factor Surveillance System, 2009. Prev Chronic Dis 2011;8(6):A133 http://www.cdc.gov/pcd/issues/2011/nov/11_o091.htm. PubMed î

24. Clinical guidelines on the identification, evaluation, and treatment of overweight and obesity in adults - the evidence report. National Institutes of Health. Obes Res 1998;6(Suppl 2):51S-209S. . CrossRef 诸 PubMed 法

25. Brief BRFSS. Sugar-sweetened beverage. New York State Adults 2009. New York State Department of Health; number 1003. http://www.health.ny.gov/statistics/brfss/reports/docs/brfssbrief_sugarbev_112310.pdf.

26. Chronic disease and injury in Indiana. Indiana State Department of Health; 2012. http://www.in.gov/isdh/files/ISDH_FactSheet_Comprehensive_AUG2012_publication_10_25_2012_pdf.pdf.

27. Park S, Onufrak S, Sherry B, Blanck HM. Relationship between health-related knowledge and sugar-sweetened beverage intake among US adults. J Acad Nutr Diet 2013;pii:S2212-2672(13)01674-2.

28. Zoellner J, You W, Connell C, Smith-Ray RL, Allen K, Tucker KL, et al. Health literacy is associated with Healthy Eating Index scores and sugar-sweetened beverage intake: findings from the rural Lower Mississippi Delta. J Am

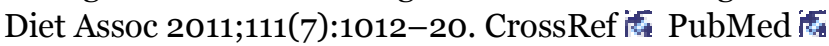

29. Segovia-Siapco G, Singh P, Haddad E, Sabate J. Relative validity of a food frequency questionnaire used to assess food intake during a dietary intervention study. Nutr Cancer 2008;60(5):603-11. CrossRef i4 PubMed i

30. Hedrick VE, Savla J, Comber DL, Flack KD, Estabrooks PA, Nsiah-Kumi PA, et al. Development of a Brief Questionnaire to Assess Habitual Beverage Intake (BEVQ-15): Sugar-sweetened beverages and total beverage energy intake. J Acad Nutr Diet 2012;112(6):840-9. CrossRef if PubMed i

\section{Tables}

Table 1. Prevalence of SSBa Intake and Sociodemographic Characteristics of the Study Population and Their Associations with SSB Intake Among Adults in 6 States, Behavioral Risk Factor Surveillance System, 2011

\begin{tabular}{|c|c|c|c|c|c|c|}
\hline \multirow[b]{2}{*}{ Characteristic } & \multirow{2}{*}{$\begin{array}{c}\text { Total } \\
\text { n (\%) }\end{array}$} & \multicolumn{4}{|c|}{ Sugar-Sweetened Beverage Intake } & \multirow[b]{2}{*}{$\begin{array}{c}P \\
\text { Value }\end{array}$} \\
\hline & & $\begin{array}{c}0 \text { Times/Day, } \\
\% \text { (SE) }\end{array}$ & $\begin{array}{c}>0 \text { to }<1 \\
\text { Time/Day, \% } \\
\text { (SE) }\end{array}$ & $\begin{array}{c}1 \text { to }<2 \\
\text { Times/Day, \% } \\
\text { (SE) }\end{array}$ & $\begin{array}{c}\geq 2 \\
\text { Times/Day, } \\
\% \text { (SE) }\end{array}$ & \\
\hline \multicolumn{2}{|c|}{ Total sample $(\mathrm{N}=38,978)$} & $30.2(0.5)$ & $45.9(0.6)$ & $13.2(0.4)$ & $10.7(0.4)$ & NA \\
\hline \multicolumn{7}{|c|}{ States $(n=38,978)$} \\
\hline Delaware & $\begin{array}{r}3,971 \\
(3.9)\end{array}$ & $29.1(1.1)$ & $44.2(1.3)$ & $15.8(1.0)$ & $10.9(0.9)$ & \multirow[t]{2}{*}{$<.001$} \\
\hline Hawaii & $\begin{array}{r}7,162 \\
(5.8)\end{array}$ & $30.5(0.8)$ & $47.0(0.9)$ & $12.1(0.6)$ & $10.4(0.6)$ & \\
\hline
\end{tabular}




\begin{tabular}{|c|c|c|c|c|c|c|}
\hline \multirow[b]{2}{*}{ Characteristic } & \multirow{2}{*}{$\begin{array}{c}\text { Total } \\
\text { n (\%)b }\end{array}$} & \multicolumn{4}{|c|}{ Sugar-Sweetened Beverage Intake } & \multirow[b]{2}{*}{$\begin{array}{c}P \\
\text { Valuec }\end{array}$} \\
\hline & & $\begin{array}{c}0 \text { Times/Day, } \\
\% \text { (SE) }\end{array}$ & $\begin{array}{c}>0 \text { to }<1 \\
\text { Time/Day, \% } \\
\text { (SE) }\end{array}$ & $\begin{array}{c}1 \text { to }<2 \\
\text { Times/Day, \% } \\
\text { (SE) }\end{array}$ & $\begin{array}{c}\geq 2 \\
\text { Times/Day, } \\
\% \text { (SE) }\end{array}$ & \\
\hline Iowa & $\begin{array}{r}5,363 \\
(12.3)\end{array}$ & $28.0(0.8)$ & $41.4(1.0)$ & $16.2(0.9)$ & $14.4(0.9)$ & \\
\hline Minnesota & $\begin{array}{c}13,804 \\
(21.4)\end{array}$ & $29.8(0.5)$ & $48.0(0.6)$ & $12.6(0.4)$ & $9.7(0.4)$ & \\
\hline New Jersey & $\begin{array}{r}4,140 \\
(34.5)\end{array}$ & $33.4(1.1)$ & $45.7(1.3)$ & $12.3(0.9)$ & $8.5(0.8)$ & \\
\hline Wisconsin & $\begin{array}{r}4,538 \\
(22.1)\end{array}$ & $26.8(0.9)$ & $46.7(1.2)$ & $13.5(0.9)$ & $13.0(0.8)$ & \\
\hline \multicolumn{7}{|l|}{ Age, y $(n=38,614)^{d}$} \\
\hline $18-29$ & $\begin{array}{r}3,070 \\
(19.3)\end{array}$ & $11.9(1.2)$ & $52.4(1.8)$ & $18.9(1.4)$ & $16.9(1.2)$ & \multirow{6}{*}{$<.001$} \\
\hline $30-39$ & $\begin{array}{r}4,325 \\
(17.0)\end{array}$ & $19.6(1.0)$ & $49.2(1.5)$ & $14.9(1.1)$ & $16.3(1.2)$ & \\
\hline $40-49$ & $\begin{array}{r}6,241 \\
(19.0)\end{array}$ & $30.2(1.1)$ & $46.7(1.2)$ & $11.8(0.8)$ & $11.3(0.8)$ & \\
\hline $50-59$ & $\begin{array}{r}8,650 \\
(19.0)\end{array}$ & $38.3(0.9)$ & $44.3(1.0)$ & $10.9(0.6)$ & $6.5(0.5)$ & \\
\hline $60-69$ & $\begin{array}{r}8,081 \\
(13.3)\end{array}$ & $42.5(1.1)$ & $41.0(1.2)$ & $10.6(0.8)$ & $5.9(0.5)$ & \\
\hline$\geq 70$ & $\begin{array}{r}8,247 \\
(12.5)\end{array}$ & $46.6(1.0)$ & $38.3(1.0)$ & $10.7(0.7)$ & $4.3(0.4)$ & \\
\hline \multicolumn{7}{|l|}{$\operatorname{Sex}(n=38,978)^{d}$} \\
\hline Male & $\begin{array}{c}15,956 \\
(49.1)\end{array}$ & $23.3(0.6)$ & $47.7(0.9)$ & $15.8(0.7)$ & $13.1(0.6)$ & \multirow{2}{*}{$<.001$} \\
\hline Female & $\begin{array}{r}23,022 \\
(50.9)\end{array}$ & $36.8(0.6)$ & $44.1(0.7)$ & $10.7(0.4)$ & $8.4(0.4)$ & \\
\hline \multicolumn{7}{|c|}{ Race/ethnicity $(n=36,849) d$} \\
\hline White, non-Hispanic & $\begin{array}{r}29,907 \\
(77.1)\end{array}$ & $32.5(0.5)$ & $45.0(0.6)$ & $12.8(0.4)$ & $9.7(0.4)$ & \multirow{4}{*}{$<.001$} \\
\hline Black, non-Hispanic & $\begin{array}{r}1,893 \\
(6.9)\end{array}$ & $18.9(2.3)$ & $46.6(2.7)$ & $17.9(2.0)$ & $16.6(2.1)$ & \\
\hline Hispanic & $\begin{array}{r}1,483 \\
(8.9)\end{array}$ & $21.4(2.0)$ & $47.7(2.7)$ & $14.9(1.7)$ & $15.9(2.2)$ & \\
\hline Other, non-Hispanic & $\begin{array}{r}3,566 \\
(7.1)\end{array}$ & $26.8(1.6)$ & $54.2(2.0)$ & $12.1(1.5)$ & $6.9(0.9)$ & \\
\hline \multicolumn{7}{|c|}{ Education level $(n=38,907)^{d}$} \\
\hline$<$ High school & $\begin{array}{r}2,071 \\
(10.8)\end{array}$ & $23.9(1.6)$ & $42.4(2.1)$ & $18.3(1.5)$ & $15.4(1.6)$ & \multirow{4}{*}{$<.001$} \\
\hline High school graduate & $\begin{array}{r}11,091 \\
(30.7) \\
\end{array}$ & $27.9(0.8)$ & $41.4(1.0)$ & $15.6(0.8)$ & $15.1(0.8)$ & \\
\hline Some college & $\begin{array}{r}11,007 \\
(30.3)\end{array}$ & $29.2(0.8)$ & $47.3(1.0)$ & $12.8(0.7)$ & $10.7(0.6)$ & \\
\hline College graduate & $\begin{array}{c}14,738 \\
(28.2)\end{array}$ & $36.0(0.8)$ & $50.6(0.9)$ & $9.2(0.5)$ & $4.2(0.3)$ & \\
\hline \multicolumn{7}{|c|}{ Marital status $(n=38,806)^{d}$} \\
\hline Married & & $34.2(0.6)$ & $46.7(0.6)$ & $11.4(0.4)$ & $7.7(0.4)$ & $<.001$ \\
\hline
\end{tabular}


Preventing Chronic Disease | Consumption of Sugar-Sweetened Beverages Among US A... Page 8 of 12

\begin{tabular}{|c|c|c|c|c|c|c|}
\hline \multirow[b]{2}{*}{ Characteristic } & \multirow{2}{*}{$\begin{array}{c}\text { Total } \\
\text { n (\%) }\end{array}$} & \multicolumn{4}{|c|}{ Sugar-Sweetened Beverage Intake } & \multirow[b]{2}{*}{$\begin{array}{c}P \\
\text { Value }^{c}\end{array}$} \\
\hline & & $\begin{array}{c}0 \text { Times/Day, } \\
\% \text { (SE) }\end{array}$ & $\begin{array}{c}>0 \text { to }<1 \\
\text { Time/Day, \% } \\
\text { (SE) }\end{array}$ & $\begin{array}{c}1 \text { to }<2 \\
\text { Times/Day, \% } \\
\text { (SE) }\end{array}$ & $\begin{array}{c}\geq 2 \\
\text { Times/Day, } \\
\% \text { (SE) }\end{array}$ & \\
\hline & $\begin{array}{r}21,774 \\
(53.5)\end{array}$ & & & & & \\
\hline Single & $\begin{array}{r}6,774 \\
(29.0)\end{array}$ & $17.2(0.9)$ & $48.6(1.4)$ & $17.1(1.1)$ & $17.0(1.0)$ & \\
\hline Divorced/separated/widowed & $\begin{array}{c}10,258 \\
(17.6)\end{array}$ & $39.3(0.9)$ & $38.8(0.9)$ & $12.4(0.6)$ & $9.5(0.6)$ & \\
\hline \multicolumn{7}{|c|}{ Annual household income, $\$(n=38,978)$} \\
\hline$<25,000$ & $\begin{array}{r}8,048 \\
(20.9)\end{array}$ & $24.6(0.9)$ & $43.0(1.3)$ & $15.8(1.0)$ & $16.6(1.0)$ & \multirow{5}{*}{$<.001$} \\
\hline $25,000-49,999$ & $\begin{array}{r}9,523 \\
(22.4)\end{array}$ & $29.2(0.9)$ & $45.1(1.0)$ & $15.0(0.8)$ & $10.8(0.6)$ & \\
\hline $50,000-74,999$ & $\begin{array}{r}5,963 \\
(14.2)\end{array}$ & $29.4(1.1)$ & $50.3(1.3)$ & $11.4(0.8)$ & $8.9(0.9)$ & \\
\hline$\geq 75,000$ & $\begin{array}{r}10,653 \\
(28.3)\end{array}$ & $34.3(0.9)$ & $49.6(1.0)$ & $9.7(0.7)$ & $6.4(0.5)$ & \\
\hline Don't know/refused/missing & $\begin{array}{c}4,791 \\
(14.2)\end{array}$ & $32.3(1.5)$ & $39.7(1.7)$ & $15.6(1.5)$ & $12.4(1.3)$ & \\
\hline
\end{tabular}

Abbreviations: SSB, sugar-sweetened beverage; SE, standard error; NA, not applicable.

a SSBs include nondiet soda and fruit drinks that are not $100 \%$ juice.

b Unweighted sample size and weighted percentage. Weighted percentages may not add to 100 because of rounding.

${ }^{c} X^{2}$ tests were used for each variable to examine differences across categories.

d Sample size for age, race/ethnicity, education level, and marital status may not add up to total because of missing data.

Table 2. Prevalence of Behavioral Characteristics and Their Association with Sugar-Sweetened Beveragea Intake Among Adults in 6 States, b Behavioral Risk Factor Surveillance System, 2011

\begin{tabular}{|c|c|c|c|c|c|c|}
\hline \multirow[b]{2}{*}{ Characteristic } & \multicolumn{6}{|c|}{ Sugar-Sweetened Beverage Intake } \\
\hline & $\begin{array}{l}\text { All, N } \\
(\%)^{c}\end{array}$ & $\begin{array}{c}0 \text { Times/Day, } \\
\% \text { (SE) }\end{array}$ & $\begin{array}{c}>0 \text { to }<1 \\
\text { Time } / \text { Day, \% } \\
\text { (SE) }\end{array}$ & $\begin{array}{c}1 \text { to }<2 \\
\text { Times/Day, \% } \\
\text { (SE) }\end{array}$ & $\begin{array}{c}\geq 2 \text { Times/Day, } \\
\% \text { (SE) }\end{array}$ & $\underset{d}{P}$ \\
\hline \multicolumn{7}{|c|}{ Fruit intake $(n=38,101)$} \\
\hline$<1$ time $/ \mathrm{d}$ & $\begin{array}{r}17,011 \\
(48.9)\end{array}$ & $23.9(0.6)$ & $46.6(0.8)$ & $15.9(0.7)$ & $13.6(0.6)$ & \multirow[t]{2}{*}{$<.001$} \\
\hline$\geq 1$ time $/ \mathrm{d}$ & $\begin{array}{r}21,090 \\
(51.1)\end{array}$ & $36.0(0.7)$ & $45.6(0.8)$ & $10.7(0.5)$ & $7.7(0.5)$ & \\
\hline \multicolumn{7}{|c|}{$100 \%$ fruit juice intake $(n=38,101)$} \\
\hline$<1$ time $/ \mathrm{d}$ & $\begin{array}{r}28,706 \\
(76.1)\end{array}$ & $30.4(0.5)$ & $46.1(0.6)$ & $12.6(0.4)$ & $10.9(0.4)$ & \multirow{2}{*}{.048} \\
\hline$\geq 1$ time $/ \mathrm{d}$ & $\begin{array}{r}9,395 \\
(23.9)\end{array}$ & $29.1(1.0)$ & $46.0(1.2)$ & $15.2(0.9)$ & $9.7(0.8)$ & \\
\hline \multicolumn{7}{|c|}{ Vegetable intake $(n=37,874)$} \\
\hline$<3$ times/d & $\begin{array}{r}31,933 \\
(86.8)\end{array}$ & $28.0(0.5)$ & $47.1(0.6)$ & $13.9(0.4)$ & $11.0(0.4)$ & \multirow{2}{*}{$<.001$} \\
\hline$\geq 3$ times $/ d$ & $\begin{array}{r}5,941 \\
(13.2)\end{array}$ & $42.5(1.4)$ & $40.0(1.4)$ & $8.2(0.7)$ & $9.3(1.0)$ & \\
\hline
\end{tabular}




\begin{tabular}{|c|c|c|c|c|c|c|}
\hline \multirow[b]{2}{*}{ Characteristic } & \multicolumn{6}{|c|}{ Sugar-Sweetened Beverage Intake } \\
\hline & $\begin{array}{l}\text { All, N } \\
(\%)^{c}\end{array}$ & $\begin{array}{c}0 \text { Times/Day, } \\
\% \text { (SE) }\end{array}$ & $\begin{array}{c}>0 \text { to }<1 \\
\text { Time/Day, \% } \\
\text { (SE) }\end{array}$ & $\begin{array}{c}1 \text { to }<2 \\
\text { Times/Day, \% } \\
\text { (SE) }\end{array}$ & $\begin{array}{c}\geq 2 \text { Times/Day, } \\
\%(S E)\end{array}$ & $\underset{d}{P}$ \\
\hline \multicolumn{7}{|c|}{ Leisure-time physical activity $(n=37,789)$} \\
\hline Highly active & $\begin{array}{r}13,572 \\
(33.1)\end{array}$ & $33.0(0.8)$ & $46.2(1.0)$ & $12.3(0.7)$ & $8.4(0.6)$ & \multirow{4}{*}{$<.001$} \\
\hline Active & $\begin{array}{r}7,420 \\
(19.9)\end{array}$ & $30.0(1.0)$ & $49.9(1.2)$ & $12.2(0.9)$ & $7.9(0.7)$ & \\
\hline Insufficiently active & $\begin{array}{r}7,238 \\
(20.5)\end{array}$ & $26.0(1.0)$ & $49.3(1.2)$ & $13.6(1.0)$ & $11.1(0.8)$ & \\
\hline Inactive & $\begin{array}{r}9,559 \\
(26.6)\end{array}$ & $29.1(0.9)$ & $40.9(1.1)$ & $14.7(0.8)$ & $15.3(0.9)$ & \\
\hline \multicolumn{7}{|c|}{ Smoking status $(n=38,815)$} \\
\hline Nonsmokers & $\begin{array}{r}20,855 \\
(55.4)\end{array}$ & $29.1(0.6)$ & $49.6(0.8)$ & $12.8(0.5)$ & $8.5(0.5)$ & \multirow{3}{*}{$<.001$} \\
\hline Former smokers & $\begin{array}{r}12,067 \\
(26.1)\end{array}$ & $39.3(0.9)$ & $42.8(0.9)$ & $11.1(0.7)$ & $6.8(0.5)$ & \\
\hline Current smokers & $\begin{array}{r}5,893 \\
(18.5)\end{array}$ & $20.4(0.9)$ & $39.1(1.3)$ & $17.6(1.1)$ & $22.9(1.2)$ & \\
\hline \multicolumn{7}{|c|}{ Alcohol drinking $(n=38,781)$} \\
\hline No drinking & $\begin{array}{r}15,969 \\
(38.0)\end{array}$ & $30.8(0.7)$ & $42.8(0.9)$ & $14.2(0.7)$ & $12.2(0.6)$ & \multirow{3}{*}{$<.001$} \\
\hline Any drinking & $\begin{array}{r}20,199 \\
(54.7)\end{array}$ & $29.7(0.6)$ & $48.4(0.8)$ & $12.6(0.6)$ & $9.4(0.5)$ & \\
\hline Heavy drinkinge & $\begin{array}{r}2,613 \\
(7.3)\end{array}$ & $30.4(1.9)$ & $44.4(1.9)$ & $13.1(1.3)$ & $12.1(1.3)$ & \\
\hline \multicolumn{7}{|c|}{ Weight status $(\mathrm{n}=37,065)$} \\
\hline $\begin{array}{l}\text { Underweight (BMI } \\
<18.5 \mathrm{~kg} / \mathrm{m}^{2} \text { ) }\end{array}$ & $\begin{array}{r}649 \\
(1.7)\end{array}$ & $23.5(3.0)$ & $50.7(4.9)$ & $14.4(2.6)$ & $11.5(2.6)$ & \multirow{4}{*}{.007} \\
\hline $\begin{array}{l}\text { Normal weight (BMI } \\
\left.18.5-24.9 \mathrm{~kg} / \mathrm{m}^{2}\right)\end{array}$ & $\begin{array}{r}13,139 \\
(35.8)\end{array}$ & $28.1(0.8)$ & $48.2(1.0)$ & $12.9(0.7)$ & $10.7(0.7)$ & \\
\hline $\begin{array}{l}\text { Overweight (BMI } 25 \\
-29.9 \mathrm{~kg} / \mathrm{m}^{2} \text { ) }\end{array}$ & $\begin{array}{r}13,521 \\
(35.9)\end{array}$ & $30.5(0.8)$ & $46.5(0.9)$ & $13.5(0.7)$ & $9.5(0.5)$ & \\
\hline $\begin{array}{l}\text { Obese }(\text { BMI } \geq 30 \\
\left.\mathrm{kg} / \mathrm{m}^{2}\right)\end{array}$ & $\begin{array}{r}9,756 \\
(26.6)\end{array}$ & $31.4(0.9)$ & $42.4(1.1)$ & $13.7(0.8)$ & $12.5(0.9)$ & \\
\hline
\end{tabular}

Abbreviations: SE, standard error; BMI, body mass index.

a Sugar-sweetened beverages include nondiet soda and fruit drinks that are not $100 \%$ juice.

b Delaware, Hawaii, Iowa, Minnesota, New Jersey, and Wisconsin.

c Percentages are weighted and may not total $100 \%$ because of rounding.

${ }^{d} x^{2}$ tests were used for each variable to examine differences across categories.

e More than 2 drinks per day for men and more than 1 drink per day for women.

Table 3. Prevalence and Adjusted Odds Ratios of Consuming SugarSweetened Beverages 1 or more Times Per Day Among Adults in 6 States, by Selected Characteristics, Behavioral Risk Factor Surveillance System, 2011

\begin{tabular}{|l|c|c|}
\hline \multirow{2}{*}{ Characteristic } & \multicolumn{2}{|c|}{ Sugar-Sweetened Beverage Intake $\geq 1$ Time/Dayb } \\
\cline { 2 - 3 } & $\%(\mathrm{SE})$ & Adjusted ORc (95\% CI) \\
\hline
\end{tabular}




\begin{tabular}{|c|c|c|}
\hline \multirow[b]{2}{*}{ Characteristic } & \multicolumn{2}{|c|}{ Sugar-Sweetened Beverage Intake $\geq 1$ Time/Dayb } \\
\hline & $\%$ (SE) & Adjusted ORc (95\% CI) \\
\hline \multicolumn{3}{|l|}{ State } \\
\hline Delaware & $26.7(1.2)$ & $1.26(1.07-1.48)$ \\
\hline Hawaii & $22.5(0.8)$ & $1.18(0.97-1.44)$ \\
\hline Iowa & $30.6(1.1)$ & $1.65(1.44-1.89)$ \\
\hline Minnesota & $22.2(0.6)$ & 1 [Reference] \\
\hline New Jersey & $20.8(1.1)$ & $0.90(0.75-1.07)$ \\
\hline Wisconsin & $26.5(1.1)$ & $1.29(1.12-1.49)$ \\
\hline \multicolumn{3}{|l|}{ Age, y } \\
\hline $18-29$ & $35.8(1.7)$ & $3.37(2.56-4.43)$ \\
\hline $30-39$ & $31.2(1.4)$ & $3.35(2.68-4.19)$ \\
\hline $40-49$ & $23.1(1.0)$ & $2.15(1.74-2.67)$ \\
\hline $50-59$ & $17.4(0.7)$ & $1.37(1.12-1.67)$ \\
\hline $60-69$ & $16.5(0.9)$ & $1.15(0.93-1.42)$ \\
\hline$\geq 70$ & $15.1(0.8)$ & 1 [Reference] \\
\hline \multicolumn{3}{|l|}{ Sex } \\
\hline Male & $28.9(0.8)$ & $1.81(1.59-2.05)$ \\
\hline Female & $19.1(0.6)$ & 1 [Reference] \\
\hline \multicolumn{3}{|l|}{ Race/ethnicity } \\
\hline White, non-Hispanic & $22.5(0.5)$ & 1 [Reference] \\
\hline Black, non-Hispanic & $34.5(2.6)$ & $1.41(1.08-1.83)$ \\
\hline Hispanic & $30.9(2.5)$ & $1.06(0.79-1.41)$ \\
\hline Other, non-Hispanic & $19.0(1.7)$ & $0.79(0.60-1.04)$ \\
\hline \multicolumn{3}{|l|}{ Education level } \\
\hline$<$ High school & $33.7(2.0)$ & $1.99(1.54-2.59)$ \\
\hline High school graduate & $30.7(1.0)$ & $2.03(1.71-2.41)$ \\
\hline Some college & $23.5(0.8)$ & $1.49(1.27-1.74)$ \\
\hline College graduate & $13.4(0.6)$ & 1 [Reference] \\
\hline \multicolumn{3}{|l|}{ Marital status } \\
\hline Married & $19.1(0.5)$ & 1 [Reference] \\
\hline Single & $34.2(1.3)$ & $1.06(0.88-1.28)$ \\
\hline Divorced/separated/widowed & $21.9(0.8)$ & $1.14(0.98-1.32)$ \\
\hline \multicolumn{3}{|l|}{ Annual household income, \$ } \\
\hline$<25,000$ & $32.4(1.2)$ & $1.4^{\mathrm{d}}(1.18-1.83)$ \\
\hline $25,000-49,999$ & $25.8(0.9)$ & $1.3^{\mathrm{d}}(1.11-1.61)$ \\
\hline $50,000-74,999$ & $20.3(1.1)$ & $1.14(0.94-1.38)$ \\
\hline$\geq 75,000$ & $16.1(0.8)$ & 1 [Reference] \\
\hline Don't know/refused/missing & $28.0(1.7)$ & $1.56(1.21-2.00)$ \\
\hline \multicolumn{3}{|l|}{ Fruit intake } \\
\hline$<1$ time $/$ d & $29.5(0.8)$ & $1.37(1.20-1.56)$ \\
\hline
\end{tabular}




\begin{tabular}{|c|c|c|}
\hline \multirow[b]{2}{*}{ Characteristic } & \multicolumn{2}{|c|}{ Sugar-Sweetened Beverage Intake $\geq 1$ Time/Dayb } \\
\hline & $\%$ (SE) & Adjusted ORc (95\% CI) \\
\hline$\geq 1$ time $/ \mathrm{d}$ & $18.4(0.6)$ & 1 [Reference] \\
\hline \multicolumn{3}{|c|}{$100 \%$ fruit juice intake } \\
\hline$<1$ time/d & $23.5(0.6)$ & $0.73(0.63-0.85)$ \\
\hline$\geq 1$ time $/ \mathrm{d}$ & $25.0(1.1)$ & 1 [Reference] \\
\hline \multicolumn{3}{|l|}{ Vegetable intake } \\
\hline$<3$ times $/ \mathrm{d}$ & $24.9(0.5)$ & $1.13(0.93-1.36)$ \\
\hline$\geq 3$ times/d & $17.5(1.2)$ & 1 [Reference] \\
\hline \multicolumn{3}{|c|}{ Leisure-time physical activityd } \\
\hline Highly active & $20.8(0.8)$ & 1 [Reference] \\
\hline Active & $20.0(1.1)$ & $0.93(0.78-1.10)$ \\
\hline Insufficiently active & $24.7(1.2)$ & $1.14(0.95-1.36)$ \\
\hline Inactive & $30.0(1.1)$ & $1.47(1.24-1.73)$ \\
\hline \multicolumn{3}{|l|}{ Smoking status } \\
\hline Nonsmokers & $21.3(0.7)$ & 1 [Reference] \\
\hline Former smokers & $17.9(0.8)$ & $0.91(0.79-1.05)$ \\
\hline Current smokers & $40.5(1.4)$ & $1.98(1.68-2.33)$ \\
\hline \multicolumn{3}{|l|}{ Alcohol intake } \\
\hline None & $26.4(0.8)$ & 1 [Reference] \\
\hline Any & $22.0(0.7)$ & $0.81(0.70-0.92)$ \\
\hline Heavy & $25.2(1.7)$ & $0.66(0.53-0.84)$ \\
\hline \multicolumn{3}{|l|}{ Weight statusf } \\
\hline Underweight & $25.8(3.6)$ & $0.81(0.49-1.34)$ \\
\hline Normal weight & $23.6(0.9)$ & 1 [Reference] \\
\hline Overweight & $23.0(0.8)$ & $1.02(0.88-1.18)$ \\
\hline Obese & $26.2(1.1)$ & $1.10(0.93-1.30)$ \\
\hline
\end{tabular}

Abbreviations: SE, standard error; OR, odds ratio; CI, confidence interval; BMI, body mass index.

a Sugar-sweetened beverages include nondiet soda and fruit drinks that are not $100 \%$ juice.

b Reference category included adults who did not drink sugar-sweetened beverages.

c Included 32,374 adults with data for all variables studied.

d Leisure-time physical activity was categorized as highly active (>300 min/week), active (150-300 min/wk), insufficiently active (11-149 min/wk), and inactive (no physical activity).

e Alcohol intake was categorized as none, any ( $\geq 1$ drink of any alcoholic beverage during the past month but not heavy drinking), and heavy ( $>2$ drinks $/ \mathrm{d}$ for men and $>1$ drink/d for women).

f Underweight $=$ BMI $<18.5 \mathrm{~kg} / \mathrm{m}^{2}$; normal weight $=$ BMI of $18.5 \mathrm{~kg} / \mathrm{m}^{2}$ to $24.9 \mathrm{~kg} / \mathrm{m}^{2} ;$ overweight $=\mathrm{BMI}$ of $25.0 \mathrm{~kg} / \mathrm{m}^{2}$ to $29.9 \mathrm{~kg} / \mathrm{m}^{2}$; obese $=$ BMI $\geq 30 \mathrm{~kg} / \mathrm{m}^{2}$.

\section{Comment on this article at PCD Dialogue}

Learn more about PCD's commenting policy

The opinions expressed by authors contributing to this journal do not necessarily reflect the opinions of the U.S. Department of Health and Human Services, the Public Health Service, the Centers for Disease Control and Prevention, or the authors' affiliated institutions. 
Preventing Chronic Disease | Consumption of Sugar-Sweetened Beverages Among US ... Page 12 of 12

For Questions About This Article Contact pcdeditor@cdc.gov

Page last reviewed: July 24, 2014

Page last updated: July 24, 2014

Content source: National Center for Chronic Disease Prevention and Health Promotion

Centers for Disease Control and Prevention 1600 Clifton Rd. Atlanta, GA 30333, USA

800-CDC-INFO (800-232-4636) TTY: (888) 232-6348 - Contact CDC-INFO

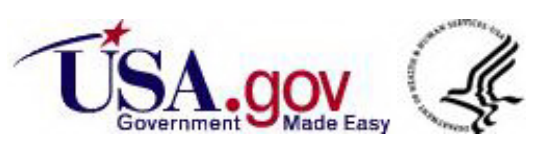

